\title{
Multiplex Detection of Rotavirus A, B, C, Norovirus GI and GIl, Adenovirus, Astrovirus and Sapovirus in a Single PCR System in Stool Samples From Acute Diarrhea Children
}

\section{Wei Li}

Zhejiang University School of Medicine Children's Hospital

\section{Weiwei Li}

Jiangsu bioperfectus biotechology LTD

\section{Ran Tao}

Zhejiang University School of Medicine Children's Hospital

\section{Wenqing Xiang}

Zhejiang University School of Medicine Children's Hospital

\section{Mingming Zhou}

Zhejiang University School of Medicine Children's Hospital

Jingan Lou

Zhejiang University School of Medicine Children's Hospital Jie Chen

Zhejiang University School of Medicine Children's Hospital

Jian-hua Mao ( $\nabla$ chweige@zju.edu.cn )

Zhejiang University School of Medicine Children's Hospital https://orcid.org/0000-0001-7501-5707

\section{Research}

Keywords: real-time RT-PCR combine melting curve analysis, virus, acute diarrhea, children

Posted Date: November 20th, 2020

DOI: https://doi.org/10.21203/rs.3.rs-111216/v1

License: (c) (1) This work is licensed under a Creative Commons Attribution 4.0 International License. Read Full License 


\section{Abstract}

Background: Early and accurate identification of infection viruses among children can benefit the personalized medical treatment and management, and reduce the future occurrence of serious symptoms. Thus, it is critical to develop a high-throughput multiplex real-time RT-PCR method to improve the accuracy and efficiency in routine clinical lab tests. Here, we developed a RT-PCR combined with melting curve analysis (RRCMC) method for simultaneous detection of rotavirus $\mathrm{A}, \mathrm{B}, \mathrm{C}$, norovirus $\mathrm{GI}$ and GII, adenovirus, astrovirus and sapovirus.

Results: Stool samples were collected from 160 children with acute diarrhea and tested by RRCMC assay. A total of 71 patients were tested positive with norovirus, adenovirus or rotavirus. The RRCMC assay has high specificity. There is no internal cross-reaction through the 8 diarrhea viruses and no cross-reaction of other commonly intestinal pathogens and human genome. The detection limit was ranging from $1 \times 10^{2}$ to $1 \times 10^{5}$ copies $/ \mathrm{ml}$ for each diarrhea virus.

Conclusions: In conclusion, the RRCMC method is a suitable rapid clinical test for infection viruses, with the advantages of high-throughput, low cost, high sensitivity, and specificity.

\section{Background}

Virus infection was most common cause of children $<5$ years old with acute diarrhea. Pathogens include rotavirus, norovirus, adenovirus, astrovirus and sapovirus. Rotaviruses are double-stranded RNA viruses and belong to family of reoviridae which can be divided into three subtypes: $A, B$, and C. Rotavirus is the leading known cause of severe gastroenteritis in infants and young children worldwide [1,2]. Norovirus is a non-enveloped, small RNA virus that contains a single stranded, positive-sense, polyadenylated RNA genome. Globally, noroviruses was associated with approximately one-fifth of all diarrhea cases [3]. Norovirus can be divided into five groups, of which norovirus GI and norovirus GIl groups are mainly related to humans [4]. Human adenovirus is non-enveloped virus which belongs to the family of adenoviridae and have a linear 36-kb dsDNA genome[5]. Human adenovirus is also recognized as an important cause of diarrhea in children. Human astroviruses are small, non-enveloped positive-sense single-stranded RNA viruses in the astroviridae family which are a major cause of diarrhea in children, the elderly, and immunocompromised people [6]. Sapovirus is a member of the Caliciviridae family, and a single-stranded positive sense RNA virus. Sapovirus infections primarily affect children aged less than 5 years, causing mild to moderate diarrhea and outbreaks in all age groups [7].

In China, the antigen assay is the main tool for rapid screening of some viruses in many hospitals However, these techniques are insensitive and cross-reactive [8, 9]. Serological tests are also widely used as a diagnostic technique in clinical practice. However, due to the time window for antibody production, its early diagnosis value is limited [10]. Both antigen and antibody detection are not applicable for multiple diarrhea viruses. Nucleic acid detection is widely used because of its high sensitivity, specificity and early diagnosis. At present, clinical nucleic acid diagnosis is mostly based on the detection of DNA / 
RNA of diarrhea related virus. However, due to the limitation of the number of fluorescent dyes and labeled probes, it is impossible to detect more pathogens in one tube of detection solution [11-13]. In this study, we developed a Multiplex Probe Melting Curve analysis for detecting rotavirus A, B, C, norovirus GI and GIl, adenovirus, astrovirus and sapovirus in one PCR tube.

\section{Methods}

\section{Study population}

From March 2019 to May 2019, patients who met the following criteria were recruited in the present study: (1) Patients who visit Children's Hospital of Zhejiang University School of Medicine in the inpatient wards and outpatient departments, (2) Primary diagnosis of acute diarrhea with suspected virus infections. This study was approved by the medical ethics committee of the Children's Hospital of Zhejiang University School of Medicine (NO.2019-IRB-082). Informed consent to participate in the study was obtained from the patients and their parents.

\section{Viruses DNA/RNA extraction}

Stools were collected and mixed with $1 \mathrm{ml}$ normal saline. The mixtures were centrifuged at 6,000 rpm at $20^{\circ} \mathrm{C}$ for 30 s. $200 \mu$ supernatant was separated and DNA/RNA was extracted by SSNP-2000A nucleic acid automatic extraction instrument and Nucleic acid extraction or purification kits (Art.No: SDK60105) abovementioned instrument and kit be from Jiangsu Bioperfectus Biotechnology Technologies Co, (Jiangsu, China).

\section{Real-time RT-PCR and Melting Profile Analysis}

The principles of RRCMC are as follows: Firstly, Taqman probes labeled with the same fluorescence dyes and primers was designed to target four viruses, and each probe is designed with a not fully complementary 3' phosphorylation closed melting curve oligonucleotide. Taqman probes with sequences of varying length can be distinguished if the probes themselves, independent of hybridising to $3^{\prime}$ phosphorylation closed melting curve oligonucleotide, have different melting temperatures. Secondly, if a virus target is present, its corresponding probe is consumed during PCR amplification; the amplification curve appeared which indicated this channel viruses positive. Comparing melting profiles of the probes with negative control after the reaction reveals which probes have been consumed and melting curve decreased; this in turn indicates which targets are present in a sample.

The regents were supported by company of Jiangsu Bioperfectus Biotechnology Technologies Co, China. PCR reactions in a final volume of $30 \mu \mathrm{l}$ consist of 4 Components: $10 \mu \mathrm{l}$ of nucleic acid amplification

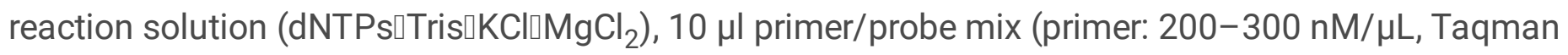
probe: $100-150 \mathrm{nM} / \mu \mathrm{L}, 3^{\prime}$ phosphorylation closed melting curve oligonucleotide: $100-300 \mathrm{nM} / \mu \mathrm{L}$ ), $5 \mu \mathrm{l}$ Enzyme mixture( M-MLV and Taq ), and $5 \mu$ template. Amplification reactions and melting profiles were performed in a real-time PCR SLAN-96P system (HONGSHI, China). The thermal profile was: $50^{\circ} \mathrm{C}$ for $20 \mathrm{~min} ; 95^{\circ} \mathrm{C}$ for $5 \mathrm{~min} ; 8$ cycles of $95^{\circ} \mathrm{C}$ for $10 \mathrm{sec}$ and $60^{\circ} \mathrm{C}$ for $40 \mathrm{sec} ; 40$ cycles of $95^{\circ} \mathrm{C}$ for $10 \mathrm{sec}$, 
$55^{\circ} \mathrm{C}$ for $30 \mathrm{sec}$, and $58^{\circ} \mathrm{C}$ for $15 \mathrm{sec}$. Fluorescence measurements were recorded during the read steps at $58^{\circ} \mathrm{C}$. Post-amplification melting profile had the following conditions: after the last cycle of PCR, heat at $95^{\circ} \mathrm{C}$ for $15 \mathrm{sec}$, cool to $20^{\circ} \mathrm{C}$ and slowly increase the temperature at speed of $0.03^{\circ} \mathrm{C} / \mathrm{s}$. The fluorescence emission data is continually collected during the rising temperatures. The negative derivative of the emission reading, with respect to temperature, is plotted against the temperature to form melting curves, and the peak of the curve corresponds to the Tm of the probe. Rotavirus $C$, astrovirus, rotavirus $B$, and norovirus GI were detected by FAM channel, and rotavirus A, sapovirus, norovirus GII, and adenovirus were detected by VIC channel.

\section{Results}

\section{Character of RRCMC assay}

Clinical strains of rotavirus A, rotavirus B, rotavirus C, GI, norovirus GIl adenovirus, sapovirus, and astrovirus were tested by RRCMC assay. As shown in Fig. 1, comparing to negative control, and according to the melting curve temperature, the viruses detection orders in turn are rotavirus $\mathrm{C}$, astrovirus, rotavirus $B$, and norovirus $\mathrm{GI}$ in FAM channel. In VIC channel of RRCMC assay, the viruses detection orders in turn are rotavirus $\mathrm{A}$, sapovirus, norovirus GII, and adenovirus with melting curve temperature rising.

\section{Sensitivity and specificity}

To determine the detection limitation of RRCMC assay, clinical strains of rotavirus A, rotavirus B, rotavirus C, GI, GIl adenovirus, sapovirus, and astrovirus were used as controls. We prepared a certain-fold dilution series from $10^{7}$ copies $/ \mathrm{mL}$ to $10^{2}$ copies $/ \mathrm{mL}$. The results showed that the detection limitation of the RRCMC method was at least as follows: rotavirus A: $1.0 \times 10^{2}$, rotavirus B: $2.0 \times 10^{3}$, rotavirus C: $1.3 \times 10^{4}$, adenovirus: $1.0 \times 10^{4}, \mathrm{Gl}: 1.0 \times 10^{5}, \mathrm{Gll}: 1.0 \times 10^{5}$, astrovirus: $4.0 \times 10^{3}$, sapovirus: $4.0 \times 10^{3}$. There is no internal cross-reaction between 8 viruses by using RRCMC assay while each virus was positive. No fluorescence was detected and no cross-reaction was found in DNAs extracted from the human genome, Salmonella, Shigella, diarrhea causing Escherichia coli, Yersinia enterocolitica, Campylobacter jejuni, Aeromonas hydrophila, Vibrio parahaemolyticus in this test.

\section{Results of clinical samples}

A total of 160 cases clinically diagnosed as acute diarrhea were enrolled into this study from March 2019 to May 2019, and stool samples were collected and tested by RRCMC assay. 108 samples were from boys while 52 samples were from girls, which yielded a male-to-female ratio of 2.08:1. There were 71 samples tested positive by RRCMC assay with positive rate of $44.38 \%$. Of these, $48(44.44 \%, 48 / 108)$ were from boys and $23(44.23 \%, 23 / 52)$ were from girls. As shown in Fig. 2, among 71 positive samples, norovirus has the highest positive rate of $10.00 \%$ (16/160) comprised 15 cases of norovirus GII $(9.38 \%$, $15 / 160)$ and 1 case of GII $(0.63 \%, 1 / 160)$, successively followed by adenovirus $(9.38 \%, 15 / 160)$, rotavirus A $(8.75 \%, 14 / 160)$ and astrovirus $(8.13 \%, 13 / 160)$, sapovirus $(3.13 \%, 5 / 160)$, norovirus (GII) and 
astrovirus co-infection (1.88\%, 3/160), rotavirus $A$ and norovirus (GII) co-infection (1.25\%, 2/160), rotavirus $A$ and astrovirus co-infection $(0.63 \%, 1 / 160)$, rotavirus $A$ and sapovirus co-infection $(0.63 \%$, $1 / 160)$, rotavirus $C$ and norovirus (GII) co-infection $(0.63 \%, 1 / 160)$. We also analyzed the age distribution of virus positive children. The median age of children with rotavirus $A$ infection was 1.33 years old (0.53$7.90)$, norovirus (GII) was 1.25 years old $(0.15-13.58)$, adenovirus was 1.74 years old $(0.50-11.74)$, astrovirus was 1.33 years old $(0.15-8.82)$ and sapovirus was 2.58 years old $(1.08-5.33)$.

\section{Discussion}

Accurate diagnosis of viral diarrhea can avoid the abuse of antibiotics after misdiagnosis as bacterial diarrhea, and carry out targeted treatment. At the same time, the clinical symptoms of these viruses are similar in the early stage of infection, but there are great differences in the clinical severity in the later stage. Rotavirus A can cause severe clinical symptoms such as dehydration and electrolyte turbulence, while Enteroadenovirus can cause mild to moderate dehydration in most children. Norovirus and sapovirus can cause significantly less clinical symptoms in children than rotavirus A [14-16]. Our results also revealed that the median age of children infected with each diarrhea virus was very close (12 years), except for astrovirus. Therefore, the accurate identification of viral pathogens early in the infection can individualize the treatment and management of children to avoid the occurrence of serious clinical symptoms. In order to detect common viruses in children diarrhea with high throughput, multiplex real-time RT-PCR was developed for the detection of adenovirus, astrovirus, rotavirus and sapovirus from stool samples in previous study [17]. However, the detection capacity of this method is not large enough.

This paper describes the development and validation of a real-time RT-PCR plus melting profile analysis (RRCMC) assay, which will allow rapid and simultaneous detection of rotavirus $A, B, C$, norovirus $\mathrm{Gl}$ and GII, adenovirus, astrovirus and sapovirus in stool samples. The cost of RRCMC assay is about 10 dollars each sample, and it takes about 3-5 hours to finish the testing process. Because of the conservative characteristics of primers and probes and the control of melting curve, RRCMC assay has high specificity. There is no internal cross-reaction between 8 diarrhea viruses. The specificity of the assay was also confirmed by testing a panel of other commonly intestinal pathogens and no-template controls and no false positive results were encountered. Our study showed that the detection limit of the RRCMC method was range from $1 \times 10^{2}$ to $1 \times 10^{5}$ copies $/ \mathrm{ml}$ for each diarrhea associated virus. Among them, the sensitivity of rotavirus detection is the highest $\left(1 \times 10^{2} \mathrm{copies} / \mathrm{ml}\right)$ and the sensitivity of norovirus $(\mathrm{Gl}$ and GII) detection is the lowest $\left(1 \times 10^{5}\right.$ copies $\left./ \mathrm{ml}\right)$.

In 160 patients with acute diarrhea, a total of 71 patients were tested positive by RRCMC. In our study, rotavirus $\mathrm{A}, \mathrm{C}$, norovirus $\mathrm{GI}$ and II, adenovirus, astrovirus and sapovirus were detected by RRCMC, and norovirus, adenovirus and rotovirus were the most common viruses caused acute diarrhea in children in study period. Rotavirus B was not detected in this study. In further studies, we will enroll more clinical samples from children with acute diarrhea. 


\section{Conclusions}

In this study, we developed a double probes plus multiple melting curve technique for detecting rotavirus A, B, C, norovirus $\mathrm{GI}$ and GII, adenovirus, astrovirus and sapovirus in one PCR tube. This method has the advantages of low cost because of single tube reaction, high sensitivity and specificity, and is suitable for general fluorescent quantitative PCR instrument, which is suitable for rapid clinical application. So the RRCMC method would be a valuable supplementary test in clinical practice.

\section{Declarations}

\section{Acknowledgements}

Not applicable.

\section{Authors' contributions}

WL, WL and JM designed the study and wrote the manuscript. RT and WX performed the laboratory work and $\mathrm{MZ}$, JL and $\mathrm{JC}$ analyzed the data. All authors read and approved the final manuscript.

\section{Funding}

This work was supported by Science and technology projects in Zhejiang Province (grant number 2019C03037).

\section{Availability of data and materials}

All data generated or analyzed during this study are included in this published article.

\section{Ethics approval and consent to participate}

This study was approved by the medical ethics committee of the Children's Hospital of Zhejiang University School of Medicine (N0.2019-IRB-082). Informed consent to participate in the study was obtained from the patients and their parents.

\section{Consent for publication}

All authors have read the manuscript and given permission to publish.

\section{Competing interests}

The authors declare that they have no competing interests.

\section{Declarations}

None. 


\section{References}

1. Soares-Weiser K, Bergman H, Henschke N, Pitan F, Cunliffe N.

Vaccines for preventing rotavirus diarrhoea: vaccines in use. ochrane Database Syst Rev. 2019(10):CD008521.

2. Li W, Xiang W, Li C, Xu J, Zhou D, Shang S. Molecular epidemiology of rotavirus A and adenovirus among children with acute diarrhea in Hangzhou, China. Gut Pathog. 2020;12:19.

3. Zhou H, Wang S, von Seidlein L, Wang X.The epidemiology of norovirus gastroenteritis in China: disease burden and distribution of genotypes. Front Med.2020;14(1):1-7.

4. Vinjé J. Adenovirusances in laboratory methods for detection and typing of norovirus. J Clin Microbiol. 2015; 53(2): 373-381

5. Gelaw A, Pietsch C, Liebert UG. Genetic diversity of human adenovirus and human astrovirus in children with acute gastroenteritis in Northwest Ethiopia. Arch Virol.2019;164(12):2985-2993.

6. Johnson C, Hargest V, Cortez V, Meliopoulos VA, Schultz-Cherry S. Astrovirus Pathogenesis. Viruses.2017; 9(1). pii: E22.

7. Sánchez GJ, Mayta H, Pajuelo MJ, Neira K, Xiaofang L, Cabrera L, et al. Epidemiology of Sapovirus Infections in a Birth Cohort in Peru. Clin Infect Dis. 2018;66(12):1858-1863.

8. Parashar UD, Nelson EA, Kang G. Diagnosis, management, and prevention of rotavirus gastroenteritis in children. BMJ. 2013;347:f7204.

9. Xiang W, Peng Z, Xu J, Shen H, Li W. Evaluation of a commercial latex agglutination test for detecting rotavirus A and human adenovirus in children's stool specimens. J Clin Lab Anal. 2020;34(5):e23208.

10. Crawford SE, Ramani S, Tate JE, Parashar UD, Svensson L, Hagbom M, et al. Rotavirus infection. Nat Rev Dis Primers. 2017;3:17083.

11. Kang G, Iturriza-Gomara M, Wheeler JG, et al. Quantitation of group A rotavirus by real-time reversetranscription-polymerase chain reaction: correlation with clinical severity in children in South India. J Med Virol. 2004;73(1):118-122.

12. Vinjé J. Adenovirusances in laboratory methods for detection and typing of norovirus. J Clin Microbiol. 2015;53(2):373-381.

13. Fu G, Miles A, Alphey L. Multiplex detection and SNP genotyping in a single fluorescence channel. PLoS One. 2012;7(1):e30340.

14. Glass RI, Parashar UD, Estes MK. Norovirus gastroenteritis. N Engl J Med. 2009;361(18):1776-1785.

15. Siqueira JAM, Oliveira DS, Carvalho TCN, Portal TM, Justino MCA, da Silva LD, et al. Astrovirus infection in hospitalized children: Molecular, clinical and epidemiological features. J Clin Virol. 2017;94:79-85.

16. Sakai Y, Nakata S, Honma S, Tatsumi M, Numata-Kinoshita K, Chiba S. Clinical severity of Norwalk virus and Sapporo virus gastroenteritis in children in Hokkaido, Japan. Pediatr Infect Dis J. 2001;20(9):849-853 
17. Bennett S, Gunson RN. The development of a multiplex real-time RT-PCR for the detection of adenovirus, astrovirus, rotavirus and sapovirus from stool samples. J Virol Methods. 2017;242:30-34.

\section{Figures}
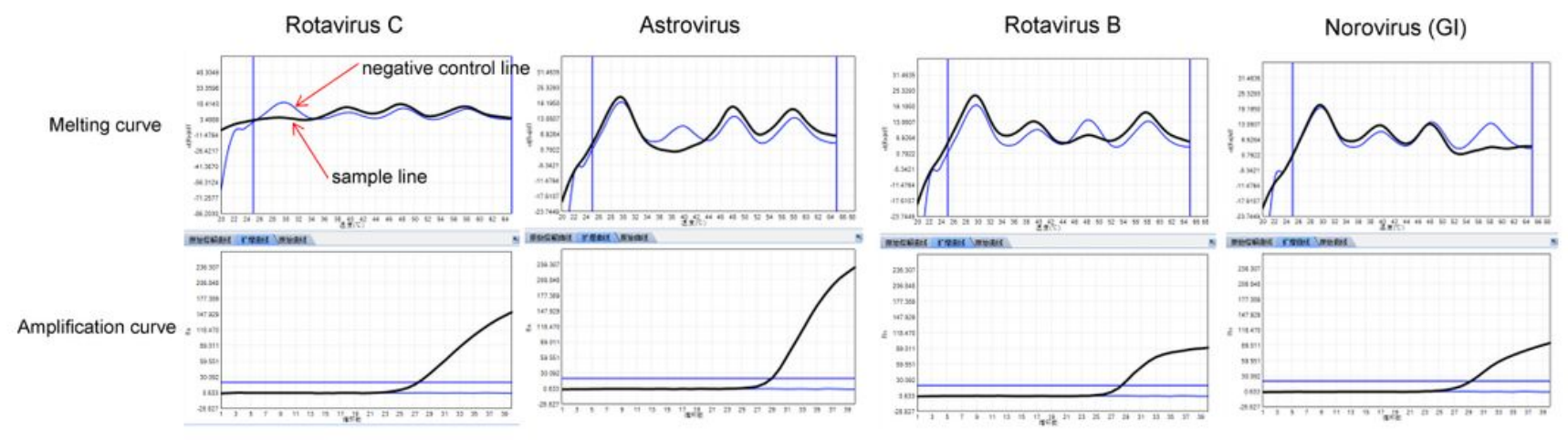

FAM channel
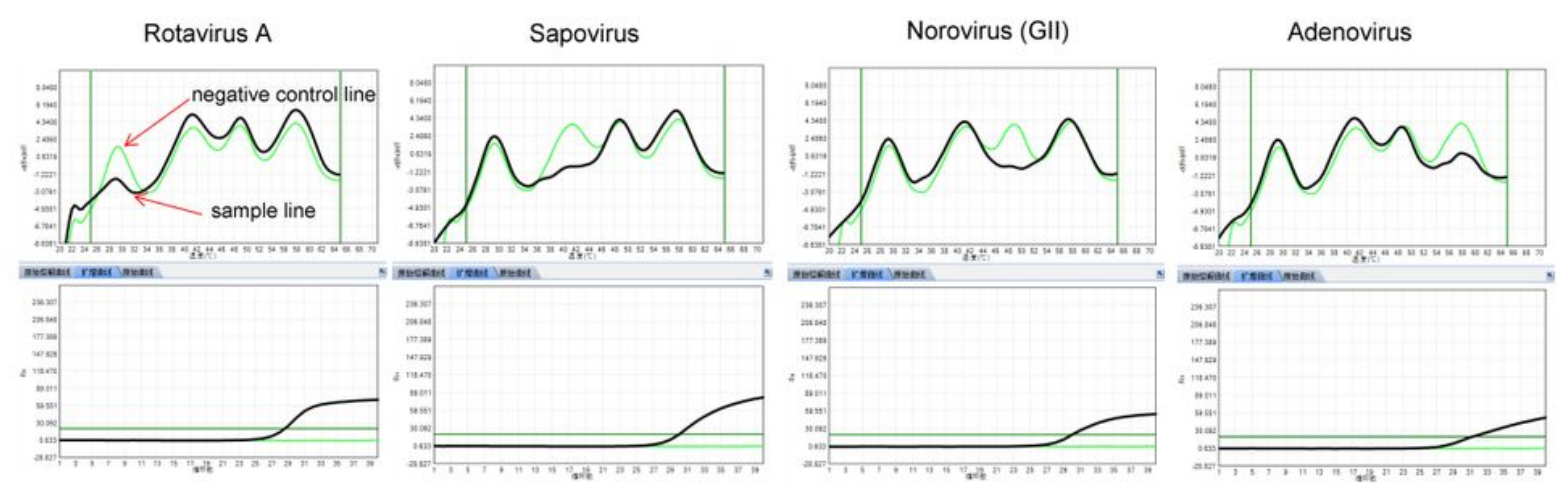

\section{Figure 1}

Amplification and melting curve of RRCMC assay 


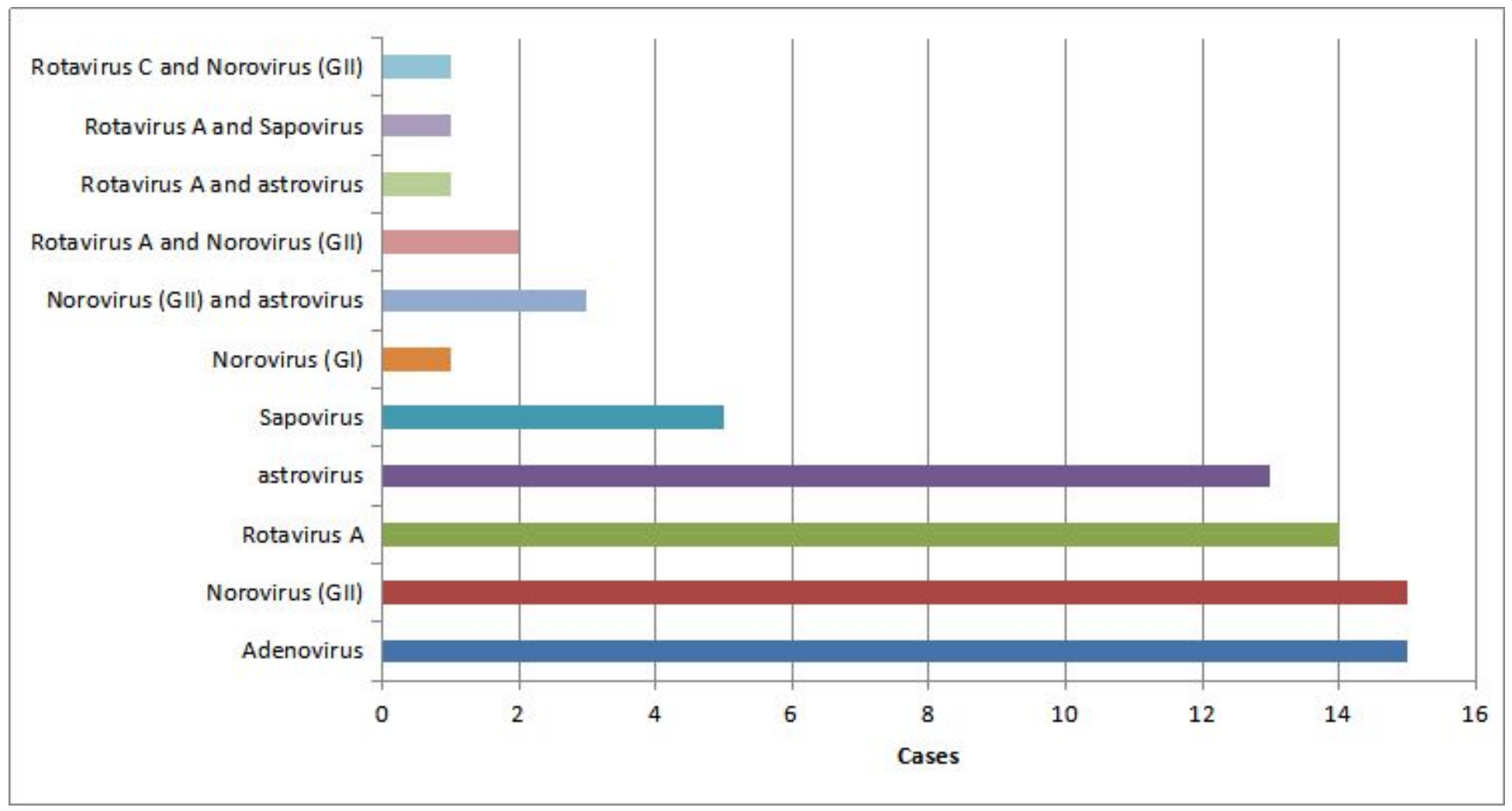

Figure 2

Results of clinical samples by using RRCMC assay 